\title{
On the Discharge of Powder by Pressure Distribution in Two-Dimensional Hoppers of Various Shapes
}

\author{
by
}

Akira TAKAMI

(Yamawaki Gakuen, Akasaka, Minato-ku, Tokyo 107)

The discharge of powder from a hopper under gravity is often stopped by the formation of bridging. The shape of hopper exerts a distinguished influence on bridging. The formation of bridging has been recognized by the fact that the bottom pressure becomes independent of the height of powder bed.

The pressure distribution in powder is calculated by solving the fundamental equation for the mechanical equilibrium in a two-dimensional model of asymmetric hoppers. Effect of the hopper shape on the formation of bridging is studied in the light of the calcuated dependence of bottom pressure on the height of powder bed. The theoretical tendency of the discharge of powder seems to agree with the experimental one in some cases.

\section{ホッパーの形状と粉体排出との関連性}

\author{
䯩見昭 ${ }^{*}$
}

(原稿受理：1976年12月 1 日)

\section{1.はしがき}

ホッパーに充てんされた粉体を重力の下に排出する場合, 架橋 現象を起こして，排出が止まり，流机なくなることがある。その ため, 排出口付近をたたいたり，かきまわしたりしなければなら ない.ホッパーから粉体を連続的に排出することは流れ作業の工 程に颃いては重要であり，種々の対策が施されている11. また， 排出についての実測や研究もある ${ }^{2)}$. 粉体の排出の難易について, 対称ホッパーである円すい型と双曲型との場合の比較を既に発表 した

本報では，この問題についてホッパー内の压力分布の見地から その形状と排出難易との関連性を解析してみた．筆者は既に円筒 容器 4 , 円すい容器》飞打ける粉体の圧力分布について取り报っ たが，その際には半径方向にも圧力分布があり，同一水平面上で 压力一定でないとした．しかし，ここでは半径方向には压力分布 がなく，同一水平面上で圧力一定とした。

\section{2. 基 礎 方 程 式}

2 次元非対称ホッパーに粉体を充てんし，自由表面を水平にす る. 二つの傾斜壁面の延長上の交点Oを原点とする (Fig. 1).

\footnotetext{
* 山脇学園 東京都港区赤坂
}

いま, 粉体内に原点 $\mathrm{O} か ら h$ の距離にある厚さ $d h$ の薄層 $\mathrm{ABCD}$ を考えよう。 $\mathrm{AB}$ 面での下向さの力は，

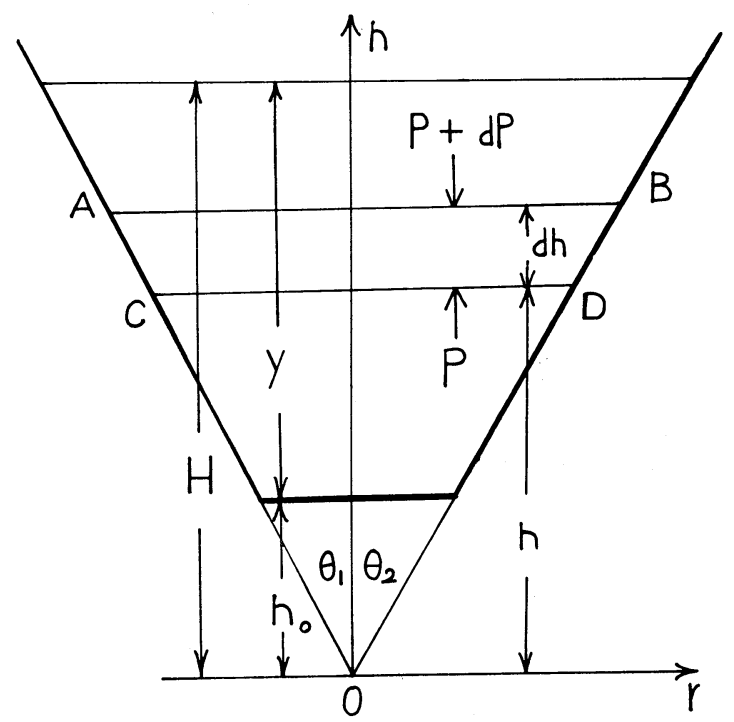

Fig. 1. Powder filled in an asymmetric two-dimensional hopper. 


$$
(P+d P) h\left(\tan \theta_{1}+\tan \theta_{2}\right)
$$

で与兄られ，CD 面での上向きの力は,

$$
P h\left(\tan \theta_{1}+\tan \theta_{2}\right)
$$

で与えられ, 重力による下向きの力はカサ密度をととして,

$$
h\left(\tan \theta_{1}+\tan \theta_{2}\right) r g d h
$$

で与えられる。

次に，壁面摩擦による力は円すい容器の場合 ${ }^{5), 6)}$ と同様にして，

$$
\begin{aligned}
\frac{d h}{\cos \theta_{1}} \mu_{w}\left(k \cos ^{2} \theta_{1}+\sin ^{2} \theta_{1}\right) P \cos \theta_{1} \\
+\frac{d h}{\cos \theta_{2}} \mu_{w}\left(k \cos ^{2} \theta_{2}+\sin ^{2} \theta_{2}\right) P \cos \theta_{2}
\end{aligned}
$$

で与兄らる，ただし，ここに $\mu_{w}$ は壁面摩擦係数， $k$ はランキ ン係数である. ランキン係数 $k$ は粉体の内部摩擦角を $\phi$ とすれば,

$$
k=\frac{1-\sin \phi}{1+\sin \phi}
$$

で与えられる．粉体の内部では $k, \mu_{w}$ を一定とする.

薄層 $\mathrm{ABCD}$ に拈ける力のつりあいから，

$$
\begin{aligned}
(P+ & d P) h\left(\tan \theta_{1}+\tan \theta_{2}\right)+h\left(\tan \theta_{1}+\tan \theta_{2}\right) \gamma g d h \\
= & P h\left(\tan \theta_{1}+\tan \theta_{2}\right)+\frac{d h}{\cos \theta_{1}} \mu_{w}\left(k \cos ^{2} \theta_{1}+\sin ^{2} \theta_{1}\right) \\
& \times P \cos \theta_{1}+\frac{d h}{\cos \theta_{2}} \mu_{w}\left(k \cos ^{2} \theta_{2}+\sin ^{2} \theta_{2}\right) P \cos \theta_{2}
\end{aligned}
$$

となる.式 (6) の両辺を $h\left(\tan \theta_{1}+\tan \theta_{2}\right) d h$ で割ると,

$$
\frac{d P}{d h}-\frac{\mu_{w}}{h} \frac{\left(k \cos ^{2} \theta_{1}+\sin ^{2} \theta_{1}\right)+\left(k \cos ^{2} \theta_{2}+\sin ^{2} \theta_{2}\right)}{\tan \theta_{1}+\tan \theta_{2}} P=-\gamma g
$$

となる。ここで, 原点 $\mathrm{O}$ と粉体自由表面との距離を $H$ とすれば, 粉体の自由表面に扮ける圧力は 0 だから，境界条件は

$$
P=0, \quad h=H
$$

である。いま，

$$
\alpha=\frac{\mu_{w}\left\{\left(k \cos ^{2} \theta_{1}+\sin ^{2} \theta_{1}\right)+\left(k \cos ^{2} \theta_{2}+\sin ^{2} \theta_{2}\right)\right\}}{\tan \theta_{1}+\tan \theta_{2}}
$$

とおいて，式 (9)を式(7)へ代入して，

$$
\frac{d P}{d h}-\frac{\alpha}{h} P=-\gamma g
$$

を得る。式 (10)を解いて境界条件 (8) を考虑すれば,

$$
\begin{array}{ll}
P=\frac{\gamma g h}{\alpha-1}\left\{1-\left(\frac{h}{H}\right)^{\alpha-1}\right\} & (\alpha \neq 1) \\
P=\gamma g h \ln \left(\frac{h}{H}\right)^{-1} & (\alpha=1)
\end{array}
$$

を得る。

次に, 原点 $\mathrm{O}$ から排出口までの距離を $h_{0}$, 粉体の層高を $y$ とす れば,

$$
h=h_{0}, \quad H=y+h_{0}
$$

となり，式 (13)を式(11)，(12)へ代入して，

$$
\begin{array}{ll}
P_{b}=\frac{\gamma g h_{0}}{\alpha-1}\left\{1-\left(\frac{h_{0}}{y+h_{0}}\right)^{\alpha-1}\right\} & (\alpha \neq 1) \\
P_{b}=\gamma g h_{0} \ln \left(\frac{h_{0}}{y+h_{0}}\right)^{-1} & (\alpha=1)
\end{array}
$$

\begin{tabular}{|c|c|c|c|c|c|c|c|c|c|c|c|c|}
\hline \multicolumn{2}{|c|}{$y(\mathrm{~cm})$} & 0 & 1 & 2 & 3 & 4 & 5 & 6 & 7 & 8 & 9 & 10 \\
\hline \multirow{4}{*}{$\begin{array}{l}P_{b} / \gamma g \\
(\mathrm{~cm})\end{array}$} & (1) & 0.0 & 1.0 & 1.9 & 2.8 & 3.7 & 4.5 & 5.3 & 6.1 & 6.9 & 7.7 & 8.5 \\
\hline & (2) & 0.0 & 1.0 & 1.9 & 2.9 & 3.8 & 4.7 & 5.6 & 6.4 & 7.3 & 8.1 & 9.0 \\
\hline & (3) & 0.0 & 1.0 & 1.9 & 2.9 & 3.7 & 4.6 & 5.5 & 6.3 & 7.1 & 7.9 & 8.7 \\
\hline & (4) & 0.0 & 1.0 & 1.9 & 2.8 & 3.7 & 4.6 & 5.5 & 6.3 & 7.1 & 7.9 & 8.7 \\
\hline
\end{tabular}

が得られる。式 (11)，(12) はホッパー内の圧力 $P$ を与え，式(14)，(15)
はホッパーの底压 $P_{b}$ を与える试である。

\section{3. 定数 $\boldsymbol{a}$ と底圧 $\boldsymbol{P}_{b}$}

2 次元ホッパーの形状として 4 種類 (1)〜 (4) とする (Fig. 2). ホッパー (1)，(2) はそれぞれ $60^{\circ}$ 扣よび $30^{\circ}$ の角すいホッパー， (3) は垂直壁を有するもの，(4) は非効称 ホッパーの性能をもつと

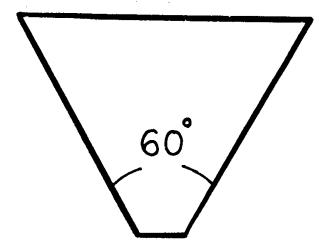

(1)

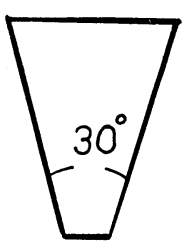

(2)

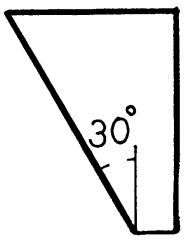

(3)

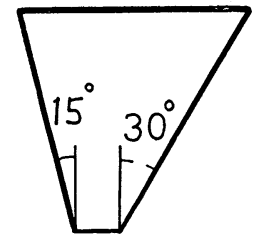

(4)
Fig. 2. Two-dimensional hoppers of various shapes.

Table I. Calculated values of the bottom pressure, $P_{b} / \gamma g$, as function of the height of powder bed $y$.

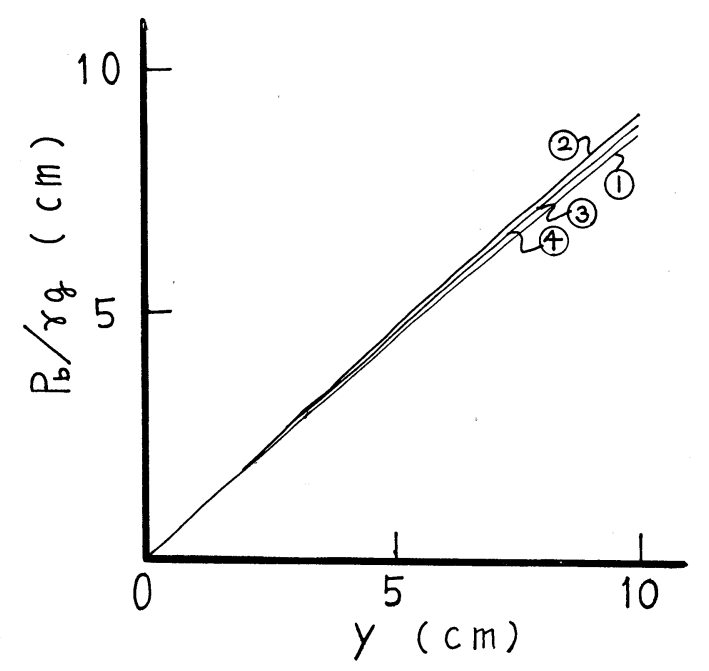

Fig. 3. Relation between $P_{b} / \gamma g$ and $y$. 
侤えられる。

ホッパーの形状が買なると式 (9)の $\theta_{1}, \theta_{2}$ が変わることになり， $\alpha$ も変わる。したがって, $\theta_{1}, \theta_{2}$ はそれぞれ (1) $\theta_{1}=\theta_{2}=30^{\circ}$, (2) $\theta_{1}=\theta_{2}=15^{\circ}$, (3) $\theta_{1}=30^{\circ}, \theta_{2}=0^{\circ}$, (4) $\theta_{1}=15^{\circ}, \theta_{2}=30^{\circ}$ であるので (1)〜 (4) の排出口がすべて $3 \mathrm{~cm}$ とすれば， $h_{0}$ の值はそれぞれ (1) $2.6 \mathrm{~cm}$, (2) $5.6 \mathrm{~cm}$, (3) $5.2 \mathrm{~cm}$, (4) $3.5 \mathrm{~cm}$ となる. い末, $k=0.1$, $\mu_{w}=0.3, \gamma=1.5 \mathrm{~g} / \mathrm{cm}^{3}$ なる值の場合を考光れば， $\alpha$ の值はそれ ぞれ (1) 0.17 , (2) 0.18 , (3) 0.22 , (4) 0.17 となる。ホッパー (1)〜 (4)について, $P_{b} / \gamma g \sim y$ 関係を計算すれば, それぞれのホッ パーの底压と層高との関係の相違が知れる (Table I, Fig. 3).

\section{4. 架 橋 状 況}

粉体がホッパー内に招いて架橋を起こす傾向は程度の差はある が，一般的に見られることであって，そのことは底圧がある層高 以上になると層高に無関係になることから知れる。この状態で $P_{b} / \gamma g$ は一定值になるが，青木はこれを $\left(P_{b} / \gamma g\right)_{m}$ で表し， $\left(P_{b} / \gamma g\right)_{m} / D_{0}$ を排出係数 ( $D_{0}$ は排出口を円としたときの直径) として, ホッパー (1)〜 (4) の排出係数を測定している (Table II) ${ }^{2)}$. これが架橋状況を表す因子，すなわち排出の難易を示すものであ り, 排出の容易な順位として粗充てんに打いては, (ア) (3) $\rightarrow(2) \rightarrow(1)$,

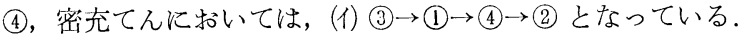

Table II. Coefficient of exhaust of various shaped hoppers.

\begin{tabular}{|c|c|c|c|c|}
\hline packing Hopper & (1) & (2) & (3) & (4) \\
\hline loose & 0.423 & 0.432 & 0.721 & 0.423 \\
\hline close & 0.313 & 0.270 & 0.405 & 0.281 \\
\hline
\end{tabular}

式 (14)，(15)によれば， $a>1$ の場合には層高 $y$ の增加とともに次 第に $P_{b}$ の增加割合は減少し, $P_{b}$ は極限值 $\gamma g h_{0} /(\alpha-1)$ になる が, $\alpha \leqq 1$ の場合には $y \rightarrow \infty$ に対しては $P_{b} \rightarrow \infty$ となる. 排出係 数の定義の条件は $P_{b} / \gamma g$ が一定值になる場合，すなわち $\alpha>1$ の 場合であるが， $\alpha \leqq 1$ の場合，ある層高に抢ける $P_{b} / \gamma g$ 亿着目す れば, Table I, Fig. 3 から $y=10 \mathrm{~cm}$ では排出の容易な順位とし て，(ウ) (2) $\rightarrow$ (3)，(4) $\rightarrow$ (1) となり，また粉体が $k=0.05, \mu_{w}=0.2$ で あれば, $y=10 \mathrm{~cm}$ では, (决 (2) $\rightarrow$ (3) $\rightarrow$ (4) $\rightarrow$ (1),$k=\mu_{w}=0.5$ であれ ば, (才) (1) $\rightarrow$ (4) $\rightarrow$ (2), (3) となる (Table III).

Table III. Calculated values of $P_{b} / \gamma g(\mathrm{~cm})$ at $y=10 \mathrm{~cm}$ for four types of hoppers.

\begin{tabular}{|c|c|c|c|c|c|}
\hline$k, \mu$ & Hopper & 1 & 2 & 3 & 4 \\
\hline $\begin{array}{c}k \\
\mu_{w}\end{array}$ & $\begin{array}{l}0.1 \\
0.3\end{array}$ & 8.5 & 9.0 & 8.7 & 8.7 \\
\hline $\begin{array}{c}k \\
\mu_{w}\end{array}$ & $\begin{array}{l}0.05 \\
0.2\end{array}$ & 9.1 & 9.5 & 9.3 & 9.2 \\
\hline $\begin{array}{c}k \\
\mu_{w}\end{array}$ & $\begin{array}{l}0.5 \\
0.5\end{array}$ & 6.0 & 5.7 & 5.7 & 5.9 \\
\hline
\end{tabular}

\section{5. あ と がき}

ホッパーの形状が粉体排出に及活す影響についての測定例がそ しいことは前報同様であり ${ }^{3)}$ ，より多くの測定例を必要とし，测 定例の数に問題はあるが，上述の測定例の範囲内で考察した。
双曲型ホッパー3) についても青木は述べているが2，，原点の決 定や計算などに仮定を多く必要とするので取り报わなかった。な お，双曲型ホッパーに近似した折線ホッパーの検討もあるが，取 り扱わなかっだ7.

壁面摩擦倸数, ランキン係数の値を壁面摩擦角, 内部摩擦角か ら得られた值を使用して定めないで，すでに発表した取り报い同 様(4),5) パラメーターとして取り报った。したがって, 壁面摩擦係 数, ランキン係数を含む $\alpha$ も影響されることになる.

式(9)に和いて， $\theta_{1}, \theta_{2}$ を一定にして $\mu_{w}, k$ を変えることは同一 ホッパーで異なる粉体を考えることに対応し， $\mu_{w}, k$ を一定にし て $\theta_{1}, \theta_{2}$ を変えることは異なる型のホッパーで同一粉体の排出を 考劣るとに対応する。

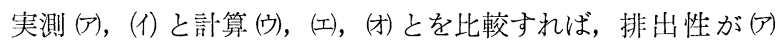
の (2)の方が (1)よりよいということは(ウ)，(代に類似し，(ア)，(1)

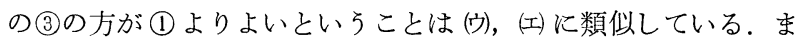

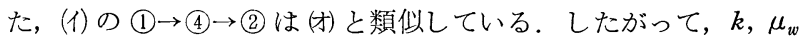
を適当にきめることによって，棓算值で青木の溳定值2)の傾向を 示せるものと括もわれる。

ホッパーからの粉体排出の難易には種々の因子があり, 複雑で あっで2)，一義的に計算されるものでなく，測定值の計算による 説明も簡単ではないが，底圧と層高との関係から粉体排出を考察 した。

本報では, 同一水平面上で圧力一定としたが，もし同一水平面 上で半径方向にも圧力分布があるとすれば, 円筒容器 ${ }^{4}$, 円すい 容器5)の場合同様に測定値が必要になる。しかし，本報で取り报 ったような 4 種類の形状のホッパーに打ける測定值は得られてい ないので，前報引同椂同一水平面上で圧力一定と仮定した。 した がって，4種類のホッパーの場合に拊ける比較のとき, いずれも 同一水平面上で圧力一定という同じ仮定の下に解析した。 このよ 弓な仮定は, 粉体内の圧力を取り披う場合に, 従来一般に行われ

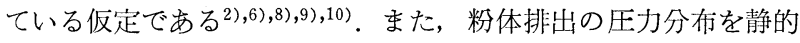
状態の圧力分布にならって表現したが，このような取り扱いも従 来行われている8).

（昭和51年10月30日 第24回レオロジー討論会にて発表）

\section{参 考 文 献}

1) Georges, P., サイロ並びにホッパー内での流動性の悪い粉 粒体の流れに関する講演録 (1971).

2) 青不隆一, 化学工学, 25, 281 (1961).

3）高見昭, 日本レオロジー学会誌，4，78 (1976).

4) Takami, A. and S. Oka, Powder Technol., 10, 295 (1974); 高見昭, 日米レオロジー学会合同会議（1975）.

5) Takami, A., Powder Technol., 14, 1 (1976).

6）青不隆一，粉体工学矿究会資料，No. 35 (1961).

7) 狩野武, 私信 (1976).

8）鲦原邦夫, 田中達美, 第11回粉体に関する討論会講演要旨 集, p. 55 (1973).

9) Theimer, O.F., Aufbereitungs-Technik, Nr. 6, 318 (1971).

10）飯田正俊, 化学工学, 22, 437 (1958).

\section{使 用 記 号}

$P \quad$ ホッパー内の粉体压 $\left[\mathrm{g} / \mathrm{cm}^{2}\right]$ 
$P_{b} \quad$ ホッパー内の粉体底压 $\left[\mathrm{g} / \mathrm{cm}^{2}\right]$

$\gamma$ 为密度 $\left[\mathrm{g} / \mathrm{cm}^{3}\right]$

$k$ ランキン係数 [-]

$\phi$ 内部摩擦角〔度〕

$\mu_{w}$ 壁面摩擦係数 [-]

$\theta_{1}$ 非対称ホッパーの壁面と軸とのなす角〔度〕 $\theta_{2}$ 非対称ホッパーの壁面と軸とのなす角〔度〕

$H$ 自由表面と原点との距離 $[\mathrm{cm}]$

$h_{0}$ 排出口と原点との距離 $[\mathrm{cm}]$

$h \quad$ 薄層と原点との距離 $[\mathrm{cm}]$

$y$ 自由表面と排出口との距離 $[\mathrm{cm}]$ 